\title{
An Update and Looking Ahead for the Journal of Occupational Rehabilitation
}

\author{
Douglas P. Gross ${ }^{1}$. Patricia A. Findley ${ }^{2}$ - Vicki L. Kristman ${ }^{3}$
}

Published online: 26 May 2020

○) Springer Science+Business Media, LLC, part of Springer Nature 2020

The Journal of Occupational Rehabilitation (JOOR) is the flagship journal in the area of occupational rehabilitation and work disability prevention. JOOR is an international and interdisciplinary forum for the publication of peerreviewed original papers on the rehabilitation, reintegration, and prevention of disability in workers. The journal offers investigations involving original data collection and research synthesis (i.e., scoping reviews, systematic reviews, and meta-analyses).

Researchers publishing in this area haverelied on the journal for decades to disseminate important findings. This is largely due to the tireless work of Founding Editor Dr. Michael Feuerstein and the rest of the senior editorial team (Dr. Patricia Findley and previously Dr. Bill Shaw) who have consistently maintained the journal's strong tradition of publishing high-quality, relevant, and meaningful original research. The important role of Editor-in-Chief includes upholding scholarly and scientific standards of the research disseminated in the journal and exploring opportunities to advance the journal (e.g., increase readership and impact). Dr. Feuerstein served remarkably well since the journal's inception and as the next Editor-in-Chief, Dr. Douglas Gross hopes to maintain this tradition while leading the journal to continued growth, a larger and more global readership, and higher impact.

We welcome suggestions and encourage readers to contact us with ideas, but we would like to highlight three innovations we are implementing to further develop and grow the journal. We are hopeful these will motivate, mobilize, and meet the needs of the growing work disability prevention research and practice community.

Douglas P. Gross

dgross@ualberta.ca

1 University of Alberta, Edmonton, AB, Canada

2 Rutgers, The State University of New Jersey, New Brunswick, NJ, USA

3 EPID@Work Research Institute, Department of Health Sciences, Lakehead University, Thunder Bay, ON, Canada

\section{Dr. Michael Feuerstein Best Paper Award}

To recognize the important role Dr. Feuerstein played in founding and building JOOR, we are pleased to announce the Dr. Michael Feuerstein Best Paper Award. The purpose of this annual award is to recognize outstanding research published in JOOR. Starting in 2021, the award will be given each January to one paper selected by the editorial board that is highly relevant to the field, methodologically rigorous, and impactful, an exemplar for the field of work disability research. All papers published in one of the four issues each year will be automatically considered for the award. The Outstanding Paper Award winner will receive a certificate and a monetary award (\$500USD). The winning article will also be made freely available for 3 months after the award is given. We feel that this award is a fitting recognition of Dr. Feuerstein's high standards of excellence in research and commitment to scholarly reporting.

\section{Improved Communications with the JOOR Community}

In collaboration with Springer, we recently updated and enhanced both the journal website and the article submission process. The website has streamlined connections between the journal information and published articles, and has been enhanced based on user feedback to make important features easier to find. The website "Online First" section allows authors to have their work rapidly available after acceptance and provides the JOOR community quick access to novel research findings. The manuscript submission process has also been streamlined and is more user-friendly than ever, while maintaining high standards of editorial oversight and peer-review. We trust these online resources are meeting user needs, but please contact us with additional ideas for improvement. Beyond the website, we hope to maintain and build new relationships through close communications with the JOOR community. The community includes readers, authors, reviewers, the editorial board, and other contributors to the journal's publishing activities. As Editor-in-Chief, Dr. Gross regularly shares highlights from the journal on 
social media. Feel free to follow on Twitter (@DP_Gross) or LinkedIn (Douglas P. Gross).

\section{Targeted Discussion of Innovative Topics and Emerging Trends}

Traditionally, JOOR has published original peer-reviewed research studies that are relevant to the journal's readership. This includes original and synthesized (i.e., systematic reviews) studies or Special Series of articles. This tradition will continue and original research will remain the primary focus of the journal. However, we will expand these offerings to explore more targeted discussion of innovative topics and emerging trends through invited editorials and brief reports. These options will still be peer-reviewed, but serve as additional mediums to highlight important topics and areas that haven't yet been rigorously evaluated. The goals would be to stimulate discussion and debate within the JOOR community, expand the field into novel areas of research, and bring original ideas and innovative methodologies to the readership.
If you have ideas for brief reports, please feel free to submit your ideas to the Editorial Team (via email to Dr. Gross atdgross@ualberta.ca) ahead of time with any questions. Next Steps

We trust that continuing the high publishing standards of JOOR and undertaking the new initiatives discussed here will further advance the field of occupational rehabilitation and work disability prevention. Thank you for your ongoing interest in the journal and efforts to read, conduct and disseminate high-quality evidence supporting JOOR's initiatives.

We look forward to our next chapter in this important global effort to reduce the burden of work disability.

Publisher's Note Springer Nature remains neutral with regard to jurisdictional claims in published maps and institutional affiliations. 